\title{
SLAP IV IN OVERHEAD SPORTS PRACTICE
}

\section{SLAP IV EM ATLETAS DE SUSPENSÃO}

\author{
Gyoguevara Sol Queiroz andrade Patriota ${ }^{1}$, Paulo Santoro Belangero ${ }^{1}$, Eduardo antônio Figueiredo ${ }^{1}$, \\ PaUlo HeNRIQUe SCHMIDT LARA ${ }^{1}$, RONALDO RONCETTI JUNIOR ${ }^{1}$, BENNo EJNISMAN ${ }^{1}$
}

1. Universidade Federal de São Paulo (UNIFESP), Departamento de Ortopedia e Traumatologia, Centro de Traumatologia do esporte (CETE), São Paulo-SP, Brazil.

\begin{abstract}
Superior labral tear from anterior to posterior (SLAP) is the most common disease in overhead sports practice. Objective: to evaluate the functional outcome after tenodesis of long head biceps tendon (LHBT) in high-performance patients with isolated SLAP lesion refractory to conservative treatment. Methods: Patients underwent the same open repair procedure, using an interference screw. Results: Both patients presented good clinical results and returned to the sport with performance similar to that prior to the injury. Conclusion: The results favor the surgical treatment of these athletes with SLAP IV. Level of Evidence IV, Série de Casos.
\end{abstract}

Keywords: SLAP lesion, Tenodesis, Sport injuries, Gymnastics, Mountaineering.

\section{RESUMO}

A lesão labral superior anteroposterior (SLAP) é a doença mais comum em atletas em suspensão do solo. Objetivo: avaliar o resultado funcional após tenodese do TCLB (tendão do cabo longo do bíceps) nos pacientes atletas em suspensão de alta performance com lesão SLAP isolada refratária ao tratamento conservador. Métodos: Os pacientes foram submetidos ao mesmo procedimento de reparo por via aberta, com uso de parafuso de interferência. Resultados: Ambos os pacientes apresentaram bons resultados clínicos e retornaram ao esporte com performance semelhante ao prévio à lesão. Conclusão: Os resultados favorecem o tratamento cirúrgico desses atletas com SLAP IV. Nível de evidencia IV, Series of Cases.

Descritores: Lesão SLAP. Tenodese. Traumatismo no esporte, Ginástica. Montanhismo.

Citation: Patriota GSQA, Belangero PS, Figueiredo EA, Lara PHS, Roncetti Jr R, Ejnisman B. Slap iv in overhead sports practice. Acta Ortop Bras. [online]. 2019;27(3):169-72. Available from URL: http://www.scielo.br/aob.

\section{INTRODUCTION}

Climbers, gymnasts and circus acrobats are athletes who perform maneuvers with the body suspended from the ground, requiring great physical effort. The appearance of osteoarticular lesions is one risk even with adequate physical exercise, with higher incidence in the upper limbs.

Shoulder injuries are superior to the suspension movements, such Superior Labral Anterior and Posterior Lesion (SLAP). The disease is secondary to the mechanism of compression and traction of the upper whole-labral body with the shoulder in hyperextension, and in some cases through maneuvers with the abducting arm associated with a flexion movement ${ }^{1}$. In the problem of conservative treatment, the surgical options are: arthroscopic repair of the labral lesion, tenodesis of the long head of bíceps tendon (LHBT) or LHBT tenotomy.

The objective of this study was to evaluate the functional outcome after LHTB tenodesis with suprapeitoral interference screws in high performance patients with SLAP lesions isolated refractory to conservative treatment.

\section{MATERIALS AND METHODS}

This is a retrospective study involving patients in suspension with SLAP IV² lesion isolated refractory to conservative treatment submitted to LHTB tenodesis in the period from 2014 to 2015. The study was approved by the Research Ethics Committee of Plataforma Brasil (INVITARE clinical research ) under protocol CAAE 70129317.5.0000.8098.

Individuals of both gender who failed to undergo the surgical treatment were included and underwent an open tenodesis of the LHBT at a reference center for shoulder and elbow surgery in São Paulo - SP. Through the evaluation of medical records, four patients underwent this surgery, and one patient operated bilaterally (total of five shoulders). Our sample consisted of: two athletes, female gender, circus acrobats (athlete A with 24 years and right and left shoulder injury (bilateral), athlete B with 26 years old and left shoulder injury). The third athlete $(C)$ is male, professional gymnast in rings, 26 years old, right handed and with left shoulder injury. The fourth athlete (D) is male, mountaineer, 26 years old, left-handed and left shoulder injury. All athletes are professional practitioners in their modalities, with an intense training profile (average of 5 hours/day, six days a week), with no previous history of injuries or shoulder surgeries.

The clinical presentation was similar in all cases, with pain in the anterior region of the shoulder when performing limb maneuvers and lateral rotation or lateral rotation elevation, always associated with the soil suspension (Table 1, Figure 1) with time the onset of symptoms 2 months ago. On physical examination they presented O'brien test

All authors declare no potential conflict of interest related to this article.

Work conducted at the Centro de Traumatologia do Esporte (CETE), Departamento de Ortopedia e Traumatologia, Universidade Federal de São Paulo (UNIFESP), São Paulo-SP, Brazil. Correspondence: Gyoguevara Sol Queiroz Andrade Patriota. Centro de Traumatologia do esporte (CETE), Rua Estado de Israel, 636, Vila Clementino, São Paulo, SP, Brasil. 04022-001. ombroecotovelo@drpatriota.com.br 
positive for SLAP lesion, with negative surprise test and relocation test. Magnetic resonance imaging showed superior labral lesion (only SLAP lesion), ${ }^{1}$ without evident biceps involvement. (Figure 2) The patients were submitted to conservative treatment with physiotherapy and anti-inflammatory / analgesic medication, but without significant improvement. The in-office evaluation involved the Visual Analogue Scale (VAS), which ranges from 0 to 10 with increasing intensity of pain; UCLA Shoulder Score ranging from 0 to 35 points, with good / excellent result $\geq 27$ and bad if $<27$ points; and the American Shoulder and Elbow Society (ASES) rating Scale that is graduated from 0-100 points, being considered good / excellent if $>$ 85 points. In addition to measuring the range of montion (ROM). ${ }^{3,4}$ All four indicators were submitted to the same surgical technique of LHBT tenodesis, open surgery, above the insertion of the tendon of the pectoralis major muscle. The patients were placed in a beach chair under anesthesia, performed arthroscopy of shouder with the

Table 1. Demographic data of professional overhead sports athletes. SLAP (Superior Labral Tear from Anterior to Posterior)

\begin{tabular}{c|c|c|c|c}
\hline Patient & A & B & C & D \\
\hline Sex & Female & Female & Male & Male \\
\hline Age (years) & 24 & 26 & 26 & 26 \\
\hline SLAP (type) & IV & IV & IV & IV \\
\hline Sport & Circus gymnast & Circus gymnast & Climber & Gymnast (rings) \\
\hline Brain dominance & Right & Right & Right & Left \\
\hline Operated shoulder & Right and left & Left & Left & Left \\
\hline
\end{tabular}

diagnosis of SLAP lesion (type IV in all cases, differing from MRI findings), accomplished LHBT tenotomy, and away other lesions associated. (Figure 3) Then the arm (about 3 to $4 \mathrm{~cm}$ ) was accessed on the left and anterior sides of the anterior axilla, identified as LHTB (medial to the insertion of the pectoral muscle) and determining the size required for a good tensioning. Made in the form of Krackov at the end of the tendon, perforated humerus (cis cortical only) proximal to the insertion of the major pectoralis muscle (according to the diameter of the tendon), LHBT tensioning was performed, and tenodesis was performed with the interferences scrow. (Figure 4)

All followed the same protocol of rehabilitation. Maintained limb immobilization for three weeks, followed by progressive gain of movement (active and passive) of the operated shoulder and training of the sports gesture. Muscular strengthening was started after 8th week. The return to the sport was possible after 3 months of surgery. The four athletes were reassessed and discharged after 12 months of surgery, but both were reassessed after 24 months of surgery for late post-surgical feedback. Both were exercising their sports activities without pain, without limitation, with a level of performance similar to that prior to injury. Statistical Package for the Social Sciences (SPSS) version 20.0 for determination of distribution by gender, age, upper limb dominance, time of return to work and sports activities, range of motion and scores of VAS, UCLA and ASES. Descriptive statistics were used to determine frequencies; measures of central tendency and measures of dispersion related to the clinical, demographic characteristics and functional scores of the shoulder in the studied patients.
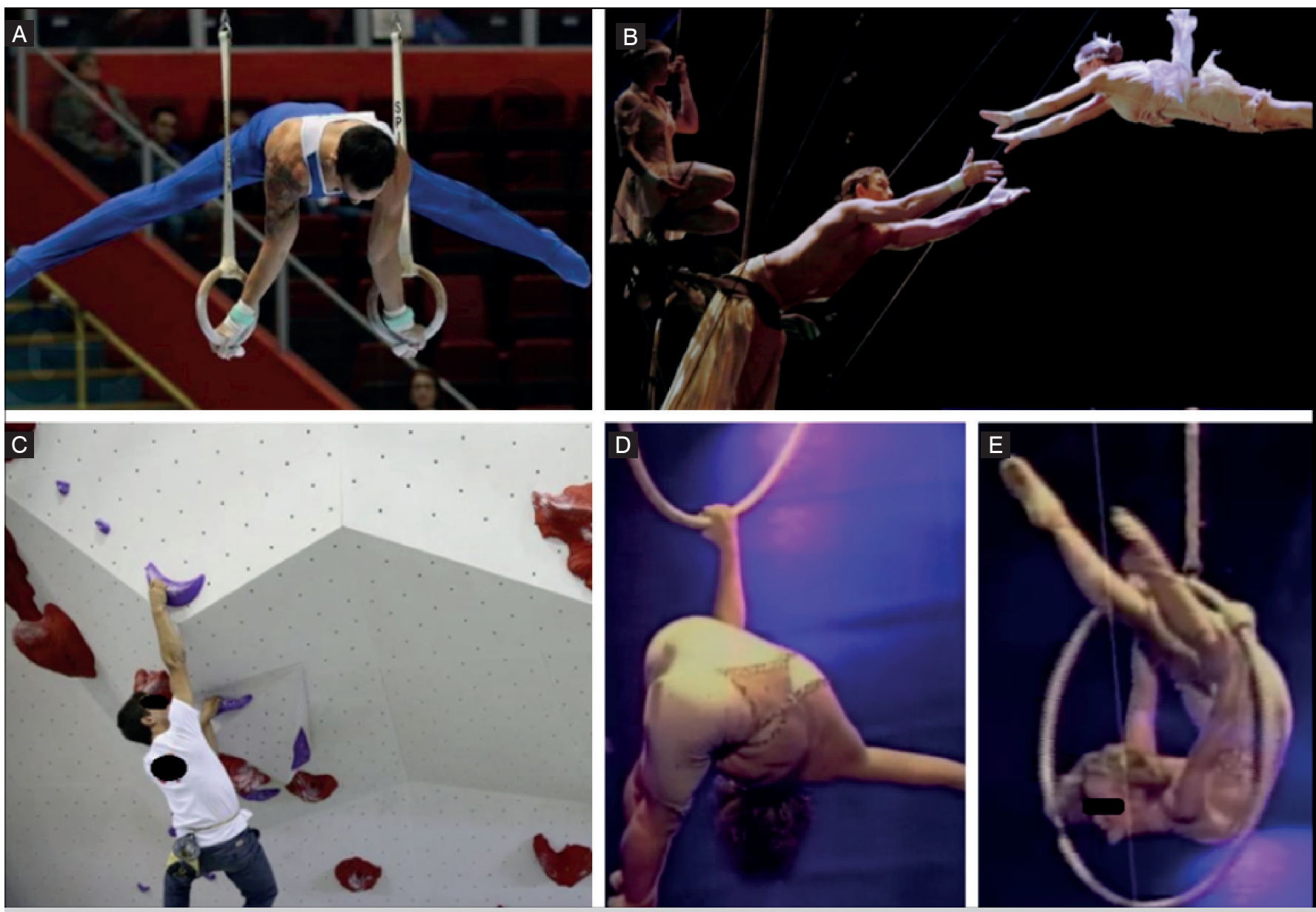

Figure 1. High performance athletes in physical activity with the body suspended from the ground. A. Gymnast in rings. B, D e E. Circus acrobat; C. Mountaineering. 

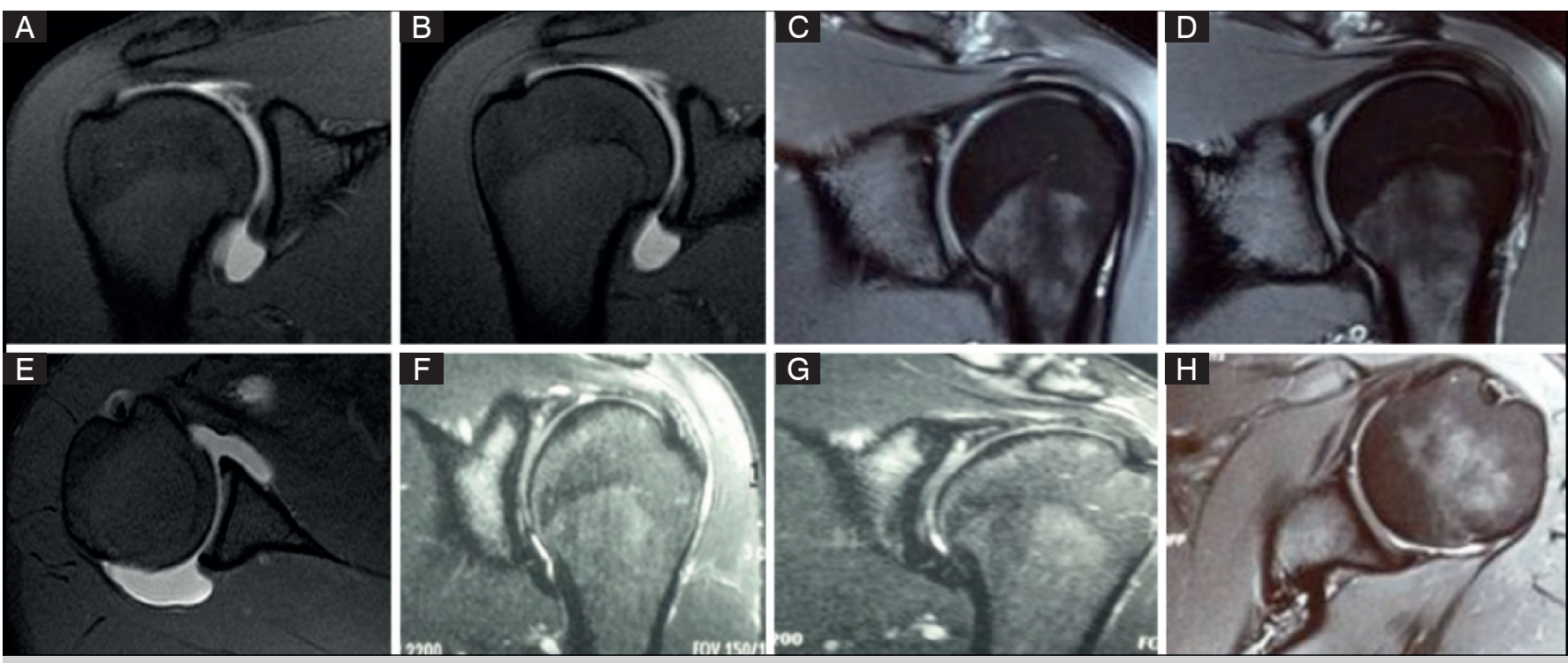

Figure 2. Magnetic resonance imaging (MRI) of the shoulder at T2. A, B, C, D, F e G. Coronal section of the MR showing SLAP lesion (only in arthroscopy can be concluded that it was SLAP IV). E e H. Axial cut shows tendinopathy of LHTB, without other concomitant lesions.
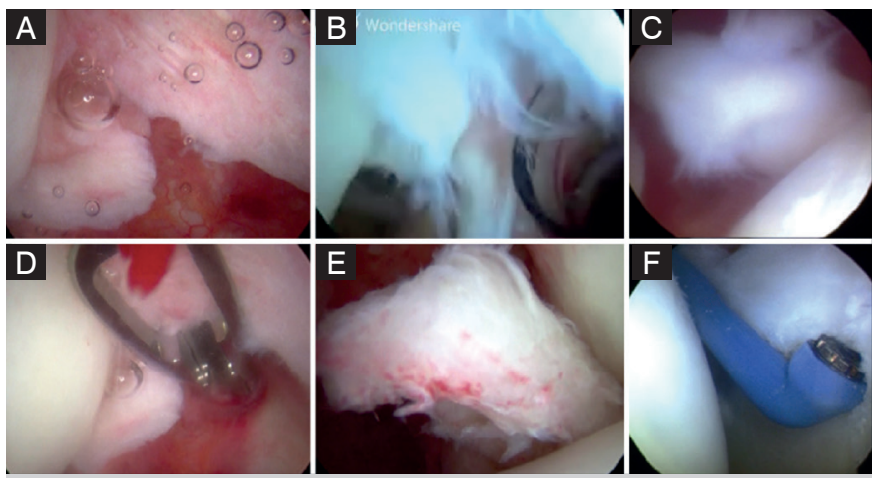

Figure 3. Images of shoulder arthroscopy (glenohumeral space). A, B, C. SLAP lesion type IV (progression of the lesion to the LHBT); D. LHTB tenotomy; E. Tenotomized biceps; F. Debridement of upper anterior-posterior posteral residual lesion.
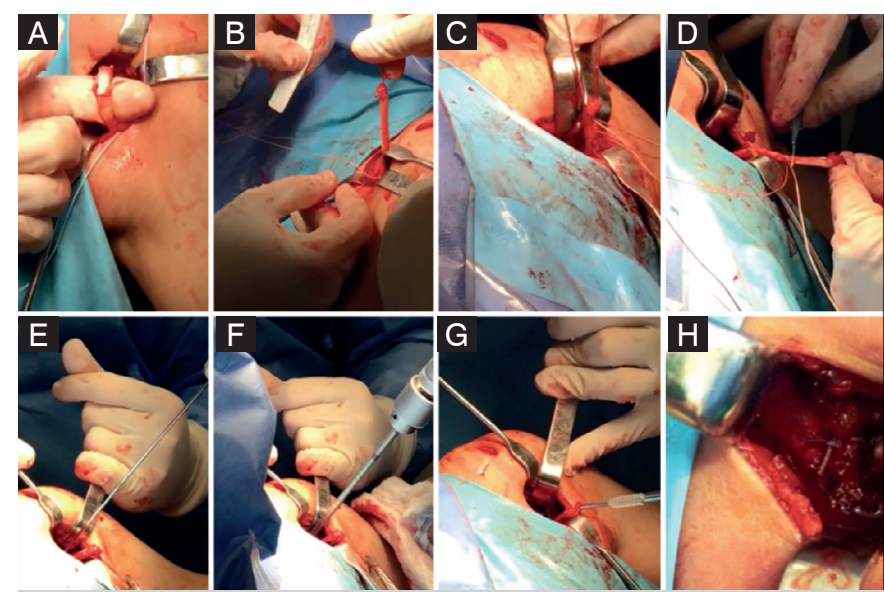

Figure 4. Images of the surgical stage open for suprapectoral tenodesis. A. Super-lateral incision to the axillary fold and identified LHBT; B. Measurement of LHBT length and diameter; C. Suture made of Krackov type after adequate measurement; D. Distracted pathological distal portion of the LHBT; E. Positioning guide wire; F. Passed cannulated drill according to tendon diameter; G. Made LHBT tenodesis with cannulated interference screw; H. Image after suprapeitoral tenodesis.
The categorical variables were expressed by absolute number (valid percentage) and the quantitative variables expressed by means and standard deviation, in case of normal distribution. Quantitative variables with non-Gaussian distribution were expressed in medians and interquartile range. Significant $a<0.05$ was considered significant. The Wilcoxon test was used to evaluate the VAS, UCLA, ASES, and ROM scores because they were unpaired data. To evaluate the qualitative variables, the Mann-Whitney test was used.

\section{RESULTS}

All four patients presented SLAP lesion type IV according to the Snyder's classification ${ }^{2}$, and mean age of $25.5 \pm 1$ and median 26 years, with two lesions in the dominant limb. The postoperative follow-up was 24 months (Table 1).

The patients returned to the sport with three months. After 12 months of returning to the sport, $100 \%$ of the functional status of the limb was reported as having a functional level equal to or greater than that prior to SLAP lesion (onset of pain). The four patients were evaluated in the pre- and postoperative period (six postoperative months) for ROM for upper limb elevation, VAS, and UCLA / ASES scores. The shoulder ROM for preoperative elevation was on average $147.2 \pm$ $8.4^{\circ}$ and in the postoperative period of $175 \pm 9.2^{\circ}$, with $p<0.001$. No loss of lateral rotation was observed postoperatively. Regarding the evaluation of the pain scale (VAS) in the preoperative period presented a mean of $3.4 \pm 0.54$ points and in the postoperative period of 0 points, with $p<0.001$. As to the scores for evaluating shoulder function with SLAP, UCLA presented a mean of $26 \pm 1.22$ points in the preoperative period and in the postoperative period of 35 points, with $p<0.001$. While ASES had a preoperative mean of $80.6 \pm 7.9$ points and in the postoperative period of $96 \pm 4.6$ points, with $p<0.001$. (Table 2)

After a 24-month follow-up, the results of the EVA and the ASES and UCLA scores maintained a maximum score.

\section{DISCUSSION}

The brachial biceps muscle has great importance in supination of the forearm (primary) and elbow flexion (secondary), accounting for $40 \%$ and $30 \%$, respectively. In relation to the shoulder, the LHBT has the following functions: static (since positioned anatomic) and dynamic 
Table 2. Escores funcionais ASES (American Shoulder and Elbow Society Rating Scale) e UCLA (University of California at Los Angeles) e escala visual analógica (EVA) pré e pós-operatório com 6 meses.

\begin{tabular}{c|c|c|c|c|c}
\hline Patient & A $^{\boldsymbol{*}}$ & $\mathbf{A} \boldsymbol{\dagger}$ & $\mathbf{B}$ & $\mathbf{C}$ & $\mathbf{D}$ \\
\hline ASES pre & 73.3 & 93 & 80 & 74 & 80 \\
\hline ASES post & 100 & 100 & 100 & 100 & 100 \\
\hline UCLA pre & 24 & 27 & 27 & 26 & 26 \\
\hline UCLA post & 35 & 35 & 35 & 35 & 35 \\
\hline VAS pre & 4 & 3 & 3 & 4 & 3 \\
\hline VAS post & 0 & 0 & 0 & 0 & 0 \\
\hline
\end{tabular}

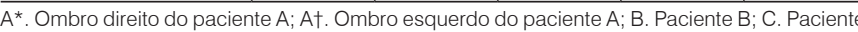
C; D. Paciente D.

humeral head depressor, as well as glenumeral stabilizer during pitches and when the shoulder is positioned in abduction and external rotation. ${ }^{5}$ The SLAP lesion has a strong relationship with throwing athletes. Subsequently, Burkhart et al., Observed that the SLAP lesion in this profile of athletes presented evolutionary pathophysiology resulting from the association of kinetic chain disorders and scapular dyskinesia. ${ }^{1}$ Gymnasts, circus acrobats and mountaineering are not subjected to high angular velocity at the shoulder as the pitchers but are exposed to long periods of overload in external rotation and traction extension of the body weight maintained in suspension. ${ }^{6}$ Caraffa et al. published an electromyographic study with overhead sports practice and observed that the most painful moments were restricted to late periods of the maneuvers and positions that the musculature presented low activity, but with high shoulder overload (favorable position for SLAP injury). ${ }^{6}$

Kibler et al. demonstrated in a systematic review for surgical treatment of the SLAP lesion there is no consensus in the literature regarding the best conduct due to the lack of consistency and accuracy of the published studies. ${ }^{7}$ The scarcity of published studies for the treatment of this lesion with suspended athletes makes it difficult to choose the best option for each case.

The main points to be questioned in the treatment chosen are: resolution of pain and level of return to the sport. Ide et al. reported that $60-75 \%$ of their patients undergoing SLAP repair were able to return to the sport with the same level of performance prior to injury. ${ }^{8}$ Boileau et al. reported that $87 \%$ of cases returned to previous sports level with tenodesis, ${ }^{9}$ similar to the results found in our study (all returned to previous performance level).

The preferred localization of LHBT tenodesis is also controversial in the orthopedic community. Tendon tenosynovitis may extend beyond the intra-articular portion and have an inflammatory component that extends through the proximal portion of the bicipital groove. To eliminate the possibility of this pathology causing persistent pain in the anterior region of the shoulder, some researchers have recommended positioning the site of tenodesis distal to the groove..$^{10-12}$ Some evidence suggests less persistence of pain and revision rates for open distal tenodesis sites compared to proximal sites using a fully arthroscopic approach. ${ }^{10}$ Other works state that there is no difference in functional scores, residual pain or complications. ${ }^{11,12}$ In our study we opted for suprapeitoral fixation by surgeon preference, and an excellent result was obtained as suggested in the most recent literature. In a study performed only with climbers by Schoffl et al., An excellent post-tenodesis functional result with mini-open interference screw and a 6-month follow-up (ASES score 97.3) were observed..$^{13}$ The level of function of the shoulder and athletic ability of the athlete presented with $96.8 \%$ of normality. ${ }^{13}$ No studies were found with surgical treatment for SLAP injury in gymnasts (suspension) or circus acrobats in the BIREME, Pubmed and Scielo platforms database. The treatment for SLAP injury in overhead athletes is still based on clinical experience of authors in the recent literature. The type of injury, age of the patient, concomitant lesions, functional demand and level of sports activity should be considered.

\section{CONCLUSION}

This study demonstrated the excellent functional outcome after surgical treatment of the SLAP lesion type IV in high performance athletes who practice sports with the body suspended from the ground (overhead). Both were submitted to open suprapectoral LHTB tenodesis. Patients evolved with resolution of pain, with no signs of instability or aesthetic deformity, with a return to sports performance similar to that prior to injury.

The suprapectoral tenodesis, with an open screw, was a safe and effective option for the treatment of SLAP IV injury in athletes with high functional demand of the shoulder.

AUTHORS' CONTRIBUTIONS: Each author contributed individually and significantly to the development of the manuscript. GSP (0000-0002-0488-0944)*: wrote and revised the manuscript, edited the images; PSB (0000-0003-4441-4742): performed the surgeries and revised the manuscript; EAF (0000-0002-78839717)*: wrote the manuscript and edited images; PHSL (0000-0002-1623-2071)*: wrote and revised the manuscript; RRJ: wrote and revised the manuscript; BE (0000-0002-3301-1457)*: performed the surgeries and revised the manuscript. *ORCID (Open Researcher and Contributor ID).

\section{REFERENCES}

1. Burkhart SS, Morgan CD, Kibler WB. The Disable Throwing Shoulder: spectrum of Pathology Part I: Pathoanatomy and biomachanics. Arthroscopy. 2003;19(4):404-20

2. Snyder SJ, Karzel RP, Del Pizzo W, Ferkel RD, Friedman MJ. SLAP lesions of the shoulder. Arthroscopy. 1990;6(4):274-9.

3. Kohn D, Geyer M. The subjective shoulder rating system. Arch Orthop Trauma Surg. 1997;116(6-7):324-8.

4. Richards RR, An KN, Bigliani LU, Friedman RJ, Gartsman GM, Gristina AG, et al. A standardized method for the assessment of shoulder function. J Shoulder Elbow Surg. 1994;3(6):347-52.

5. Lucas DB. Biomechanics of the shoulder joint. Arch Surg. 1973;107(3):425-32.

6. Caraffa A, Cerulli G, Rizzo A, Buompadre V, Appoggetti S, Fortuna M. An artrhoscopic and electromyographic study of painful shoulders in elite gymnasts. Knee Surg Sports Traumatol Arthrosc. 1996;4(1):39-42.

7. Kibler WB, Sciascia A. Current practice for the surgical treatment of SLAP lesions: a systematic review. Arthroscopy. 2016;32(4):669-83.
8. Ide J, Maeda S, Takagi K. Sports activity after arthroscopic superior labral repair using suture anchors in overhead-throwing athletes. Am J Sports Med. 2005;33(4):507-14

9. Boileau P, Parratte S, Chuinard C, Roussanne Y, Shia D, Bicknell R. Arthroscopic treatment of isolated type II SLAP lesions: biceps tenodesis as an alternative to reinsertion. Am J Sports Med. 2009;37(5):929-36.

10. Lutton DM, Gruson KI, Harrison AK, Gladstone JN, Flatow EL. Where to tenodese the biceps: proximal or distal? Clin Orthop Relat Res. 2011;469(4):1050-5.

11. Werner BC, Evans CL, Holzgrefe RE, Tuman JM, Hart JM, Carson EW, et al. Arthroscopic suprapectoral and open subpectoral biceps tenodesis: a comparison of minimum 2-year clinical outcomes. Am J Sports Med. 2014;42(11):2583-90.

12. Gombera MM, Kahlenberg CA, Nair R, Saltzman MD, Terry MA. All-arthroscopic suprapectoral versus open subpectoral tenodesis of the long head of the biceps brachii. Am J Sports Med. 2015;43(5):1077-83.

13. Schoffl V, Popp D, Dickschass J, Kupper T. Superior labral anterior-posterior lesions in rock climbers - Primary double tenodesis? Clin J Sport Med. 2011;21(3):261-3. 